\title{
Axial Flux, Modular, Permanent- Magnet Generator with a Toroidal Winding for Wind Turbine Applications
}

E. Muljadi

C.P. Butterfield

Yih-Huei Wan

National Wind Technology Center

National Renewable Energy Laboratory

Presented at

IEEE Industry Applications Conference

St. Louis, $M O$

November 5-8, 1998

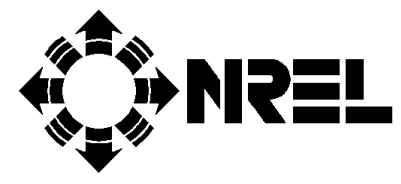

National Renewable Energy Laboratory 1617 Cole Boulevard Golden, Colorado 80401-3393

A national laboratory of the U.S. Department of Energy Managed by Midwest Research Institute for the U.S. Department of Energy under contract No. DE-AC36-83CH10093

Work performed under task number WE803020 July 1998 


\section{NOTICE}

This report was prepared as an account of work sponsored by an agency of the United States government. Neither the United States government nor any agency thereof, nor any of their employees, makes any warranty, express or implied, or assumes any legal liability or responsibility for the accuracy, completeness, or usefulness of any information, apparatus, product, or process disclosed, or represents that its use would not infringe privately owned rights. Reference herein to any specific commercial product, process, or service by trade name, trademark, manufacturer, or otherwise does not necessarily constitute or imply its endorsement, recommendation, or favoring by the United States government or any agency thereof. The views and opinions of authors expressed herein do not necessarily state or reflect those of the United States government or any agency thereof.

Available to DOE and DOE contractors from:

Office of Scientific and Technical Information (OSTI)

P.O. Box 62

Oak Ridge, TN 37831

Prices available by calling (423) 576-8401

Available to the public from:

National Technical Information Service (NTIS)

U.S. Department of Commerce

5285 Port Royal Road

Springfield, VA 22161

(703) 487-4650 


\title{
Axial Flux, Modular, Permanent-Magnet Generator with a Toroidal Winding for Wind Turbine Applications
}

\author{
E. Muljadi, C. P. Butterfield, Yih-Huei Wan \\ National Renewable Energy Laboratory \\ 1617 Cole Boulevard \\ Golden, CO 80401 \\ Tel. (303)384-6900, Fax (303)384-6999 \\ Eduard_muljadi@nrel.gov, http://www.nrel.gov/wind
}

\begin{abstract}
Permanent-magnet generators have been used for wind turbines for many years. Many small wind turbine manufacturers use direct-drive permanent-magnet generators. For wind turbine generators, the design philosophy must cover the following characteristics: low cost, light weight, low speed, high torque, and variable speed generation. The generator is easy to manufacture and the design can be scaled up for a larger size without major retooling.
\end{abstract}

A modular permanent-magnet generator with axial flux direction was chosen. The permanent magnet used is NdFeB or ferrite magnet with flux guide to focus flux density in the air gap. Each unit module of the generator may consist of one, two, or more phases. Each generator can be expanded to two or more unit modules. Each unit module is built from simple modular poles. The stator winding is formed like a torus. Thus, the assembly process is simplified and the winding insertion in the slot is less tedious.

We built a prototype of one unit module and performed preliminary tests in our laboratory. Follow up tests will be conducted in our lab to improve the design.

\section{INTRODUCTION}

Using permanent-magnet (PM) generators for small wind turbines is very common. Usually an $\mathrm{AC}$ generator with many poles operates between $10-100 \mathrm{~Hz}$. Because the generator is directly driven by the wind turbine $[1,3,5]$, it is commonly known as a direct drive generator. Many configurations use surface mounted three phase PM synchronous generators with a rectifier connected to the generator terminal.

Many types of generator concepts have been used and proposed to convert wind power into electricity. An axial flux generator with a different type of winding and a different magnet arrangement was developed [1,2]. A modular concept was proposed to reduce manufacturing costs [3]. The transverse flux generator has a higher power density than a traditional induction generator [4]. In this paper, a combination of a modular, axial flux, and torroidal stator winding are applied to a permanent-magnet generator.
Although the design is intended for wind turbine applications, this PM machine can be used for many other applications.

A wind turbine generator must be light to minimize the requirements for the tower structure. Since the wind turbine operates at low rotational speed, the generator is built with many poles. We designed, built, and tested a permanentmagnet generator for wind turbines. Several unique properties are included in this design. It uses a modular concept. Each pole is constructed individually, thus the number of poles is based on the requirements. The winding is concentric, like a torus, making it easy to assemble. The rotor core has a focusing capability with a variable magnet area, so the air gap flux density can be adjusted independent of the rotor radius. A single unit module of this generator can have single or multiple phases. Additional unit modules can be stacked in the axial direction to get more power. With this modular concept, any failure in one unit can be replaced immediately or can be bypassed, thus minimizing turbine downtime.

The dimension of the generator and the size of each component should be based on the actual wind turbine for which it is to be used. Because the purpose of the prototype unit is to prove the concept, we designed and built it with readily available components. A steady state analysis was done to determine the initial electric loading and magnetic loading. The initial loss calculation was derived. The next step of the calculation was done using finite element analysis. The flux density in the critical components, and the map of the core losses were found. No-load, rated, and short-circuit conditions can be predicted from this analysis. Any changes made were reiterated by using steady state analysis. Thus the process was repeated until the final design is ready.

A test was conducted in the lab to find the parameters of the generator and any unpredicted anomalies. Data were collected for no-load and full-load conditions.

The first section of this paper is devoted to introducing the background of the PM generator in wind turbine applications. The second section introduces the generator components. In the third section we present our analysis of the PM generator. 
In the fourth section we describe testing, and lastly, in the fifth section the conclusions are summarized.

\section{COMPONENT OF THE GENERATOR}

In this paper we discuss only one unit module of the generator. The generator consists of an eighteen-pole permanent magnet. The stator and the rotor cores are made of pre-cut transformer lamination silicon steel (gauge 26, M19). The stator and rotor cores can be made on a per pole basis, reducing the cost of complete dies required to stamp a conventional lamination configuration. The geometry of the stator and the rotor core could have been optimized, however, this project focuses on the proof of concept.

\section{A. Rotor}

The cross section of the stator and rotor pole is illustrated in Figure 1. Each pole is constructed from two identical corestacks and the permanent magnet is sandwiched in between. The rotor is constructed to allow an expansion in the axial direction, for example, to increase the magnet surface. The flux directions at the top (outer radius) and the bottom (inner radius) of the rotor pole are the opposite. Around the perimeter of the rotor, the flux direction of one pole is opposite of the flux direction in next pole, as shown by the white arrows in Figure 2. The ratio of the magnetic surface area to the pole surface area determines the focusing factor. The chosen geometry enables the designer to increase the length of the rotor core without affecting the stator geometry and vice versa.

The rotor poles are attached to a non-magnetic disk that holds the rotor cores. The shaft is attached to the disk to rotate the rotor core. A non-magnetic stainless steel belt is strapped around the rotor core to keep the rotor poles in place. Since the rotor speed is low, centrifugal force created when the rotor rotates is not very high. There are nine pole pairs on the rotor. Between two rotor poles, there is a small gap to minimize interpolar magnetic leakage.

\section{B. Stator}

The stator consists of two stator sides. There are nine poles attached to each stator side. The poles on each side are attached to a plate (not shown in Figure 2) which holds the

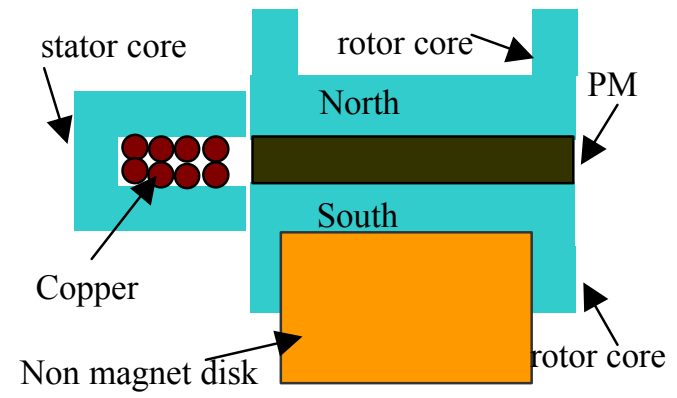

Figure 1. One pole of the stator and rotor core

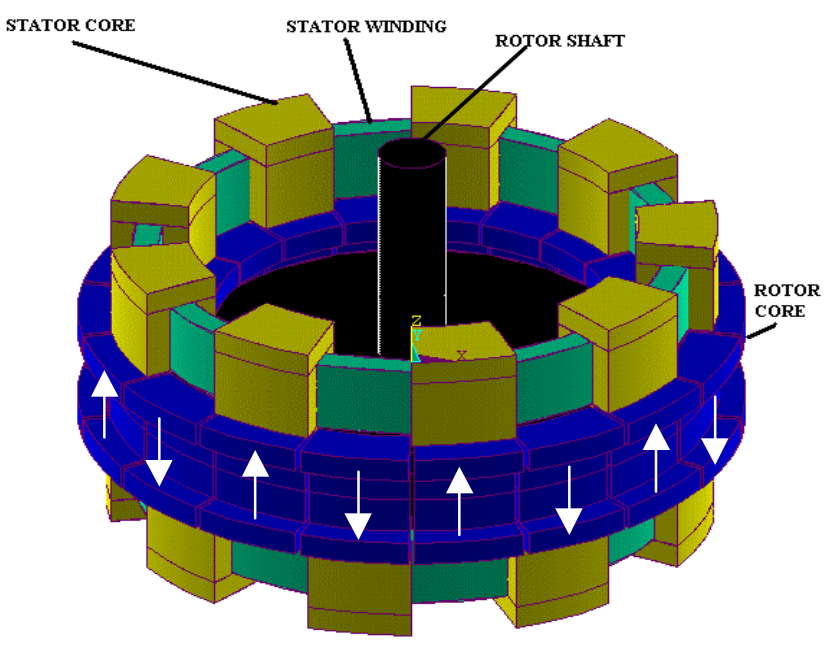

Figure 2. PM Generator with Toroidal Winding

stator poles in place. In the prototype, one side of the stator core can be rotated (within a limited angle range) with respect to the other stator side. Thus the position of the stator cores in one side can be shifted with respect to the other sides. The shift can be adjusted to control the phase shift between the first stator side and the second stator side.

\section{Stator winding}

The stator winding is wound like a torus or a washer. With a toroidal form, the stator winding can be easily assembled and automated for production. The stator winding between the stator poles is exposed to open air, which improves cooling.

One advantage of wind power systems is the location of the generator. It is mounted on a tower above the ground. The cooling mechanism is better up on the nacelle than inside a ground level building because the generator is always exposed to air flow that is proportional to the generator load. During low wind speeds, the heat transfer from the winding is lower, however, the heat generated in the winding is lower, too. The opposite is true at high wind; more heat is generated in the winding, but more air flow is available to transfer the heat away.

In this paper, one module unit is built for a single phase generator. The stator windings at the two sides are connected in parallel to generate a single phase output. The rotor shaft is attached to the stator sides through the bearings, which are attached to the stator plate. The rotor core has a width of $6.35 \mathrm{~cm}$ (2.5 in.) and a diameter of $29.2 \mathrm{~cm}$ (11.5 in.). The overall width of the generator is $16.5 \mathrm{~cm}$ (6.5 in.), excluding the two stator plates.

\section{Expansion for multimodule generation system}

The power from the stator can be actively controlled using power switches (IGBTs) or passively controlled using a diode 


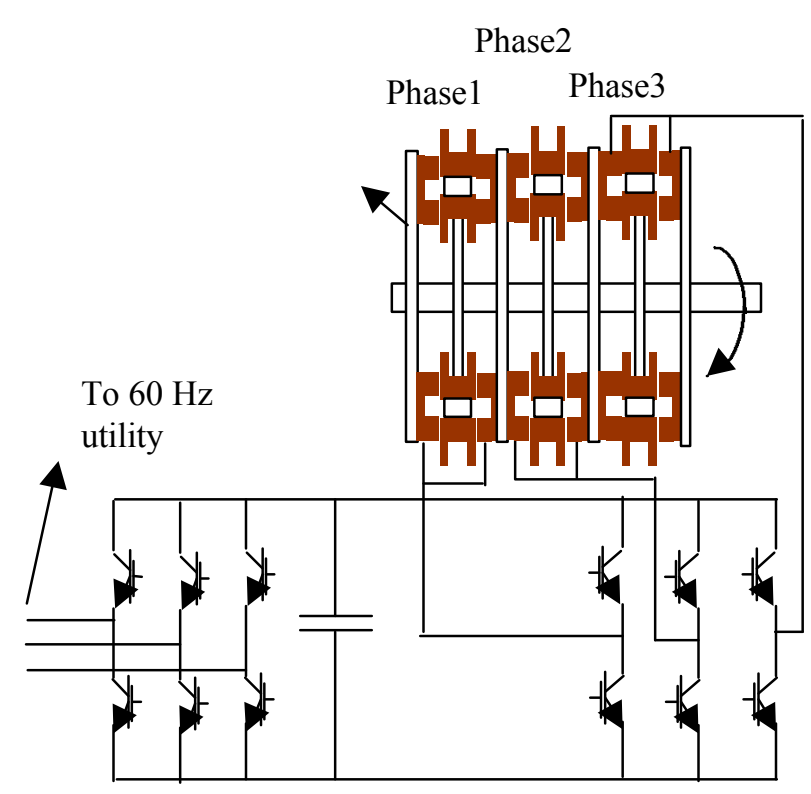

Figure 3. Expansion for multimodule generation.

rectifier. Figure 3 shows a possible configuration of the power converter to process the power generated by the generator. The generator may consist of one or more modules. In this configuration, only three unit modules are shown. Each unit module of the generator is paired with one leg module of power switches on the power converter side. Thus the power converter and the generator can be expanded in a similar fashion. The power generated is converted back to the utility via a three-phase inverter, which can be controlled to produce good power quality.

\section{DESIGN ANALYSIS}

The analysis of the generator is based on the wind turbine requirements. The steady state analysis was performed as the first step to get the first cut of design criteria. The finite element analysis was performed to refine the magnetic analysis. Finally, a dynamic analysis was performed in the lab to validate generator performance under dynamic conditions.

\section{A. Steady state analysis}

The prime mover for this generator is a wind turbine. One characteristic of wind turbines is that the rotational speed is lower than most prime movers. To avoid using a gearbox, the generator is direct driven. Multiple poles must be used to allow slow speed operation.

From steady state analysis, the following criteria are chosen:

Number of poles $=18$

Max operating frequency $=100 \mathrm{~Hz}$ (at $667 \mathrm{rpm}$ )
Number of phases per unit module $=1$ (two windings in parallel)

The electric loading:

Stator current $=11.0$ Amp RMS (at per phase voltage 58 Volt RMS)

The wire chosen is AWG 12

The current density in the slot $\mathrm{J}=3.4 \times 10^{6} \mathrm{Amp} / \mathrm{m}^{2}$

Predicted copper losses at rated current $=42$ watts

\section{B. Finite element analysis}

To analyze the magnetic circuit, the finite element method was used to compute the flux density in the generator components. The main purpose of this analysis is to get the overall picture of the saturation levels in different parts of the generator, the iron losses in the components of the generators, and the worst case of demagnetization on the permanent magnet. In the finite element analysis presented here, the generator uses a ferrite permanent magnet.

No-load condition. In the no-load condition, the magnetic

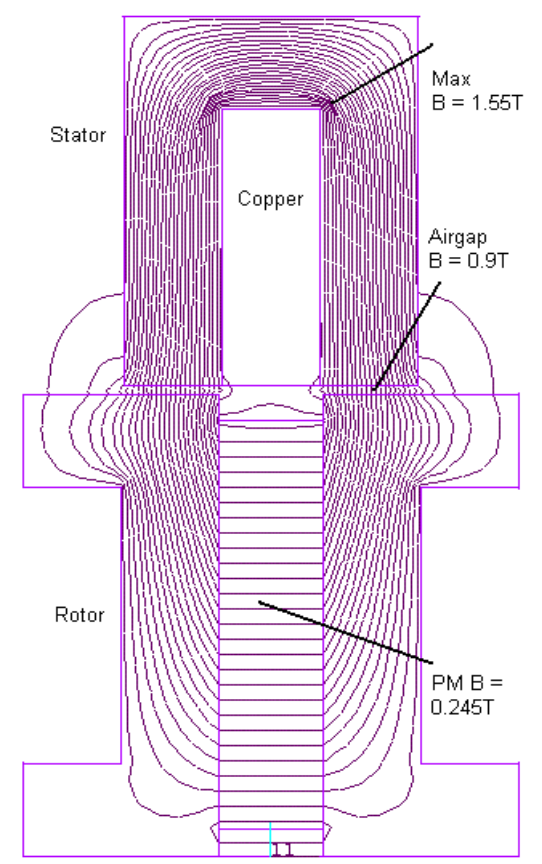

Figure 4. Flux density at no-load condition

path is analyzed to see the magnetic flux density in different parts of the magnetic paths. With the stator core in each side shifted by $180^{\circ}$ the maximum flux in the core happens when the stator core and the rotor core are aligned. Figure 4 shows the flux lines at the no-load condition. Only one side of the stator core is shown. Some flux leakage is shown such as at both ends of the rotor poles. The rotor core has low flux density with the highest flux density at the parts closest to the air gap. As shown in Figure 4, the maximum flux density 


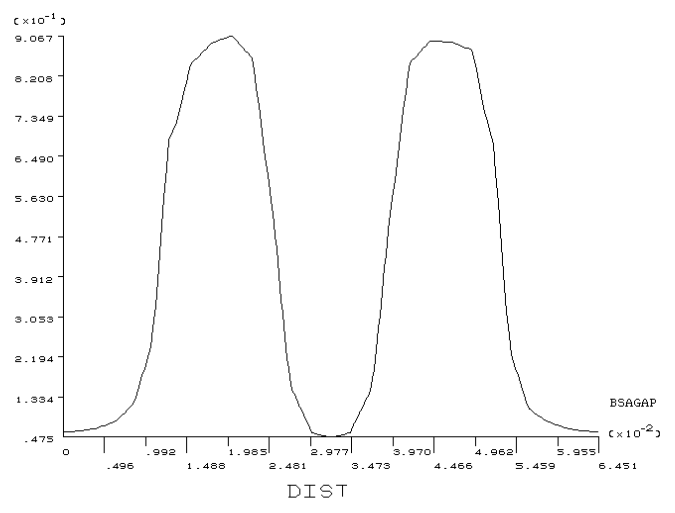

Figure 5. Flux density at no-load condition

occurs at the corner of the U-shaped stator core. Figure 5 shows the magnitude of the flux density along the horizontal line in the middle of the air gap. The maximum flux density at no load is 1.55 Tesla. The flux density at the air gap is 0.9 Tesla and the flux density at the permanent magnet is 0.24 Tesla. The stator core and the rotor core have a flux density below the saturation point.

Inductive load at rated current. In this condition, the magnetic path is analyzed to see flux reduction at the air gap at the least favorable power factor. The generator is loaded to have rated current.

Short-circuit condition. In this condition, the magnetic path is analyzed to see the demagnetization effects on the permanent magnet. In order to analyze the worst case scenario, the stator core and the rotor core are perfectly aligned and the short circuit current is applied to the stator core. In this case the short circuit current is about ten times the rated current. The result is tabulated in Table 1.

Table 1. Flux Density Comparison at Different Magnetic Paths for Different Conditions

\begin{tabular}{|l|lll|}
\hline & B airgap & B max & B at PM \\
\hline No-load & $0.91 \mathrm{~T}$ & $1.55 \mathrm{~T}$ & $0.244 \mathrm{~T}$ \\
\cline { 1 - 1 } Inductive Load (rated) & $0.89 \mathrm{~T}$ & $1.50 \mathrm{~T}$ & $0.239 \mathrm{~T}$ \\
\cline { 1 - 2 } Short Circuit & $0.70 \mathrm{~T}$ & $1.05 \mathrm{~T}$ & $0.193 \mathrm{~T}$ \\
\hline
\end{tabular}

\section{EXPERIMENTAL RESULTS}

\section{A. Experimental set up}

The experiment was conducted to observe the performance of the generator. The generator is driven by a motor via a belt. The motor is a four pole motor, with rated speed of $1800 \mathrm{rpm}$. The motor is fed by a PWM variable frequency drive. The generator speed is driven to 667 RPM. The output frequency at this rpm is $100 \mathrm{~Hz}$. The experiment is conducted only on a single unit generator. In the finite element analysis, the permanent magnet used is ferrite, however, in this experiment the permanent magnet chosen is rare earth permanent magnet $(\mathrm{NdFeB})$.

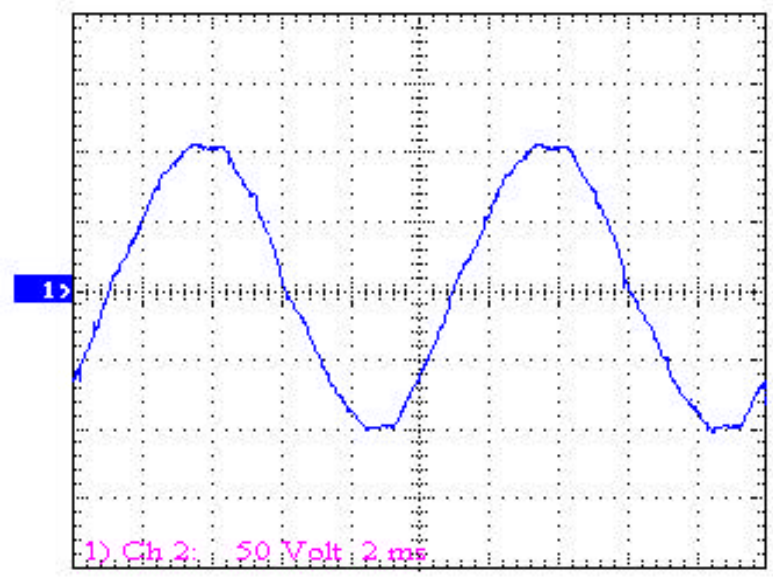

Figure 6. Open circuit woltage

\section{B. Voltage and current waveforms}

The open circuit voltage is measured at the terminal output of winding 2 (open circuit). The stator cores are shifted toward each other by 180 electrical degrees. The voltage waveform is captured from the scope, digitized, and plotted in Figure 6 and Figure 7.

In Figure 7, the generator is loaded with resistive load up to rated load at $100 \mathrm{~Hz}$. The voltage across the terminal output of the generator is a unity power factor load. Thus the current waveform is reflected by this terminal voltage waveform.

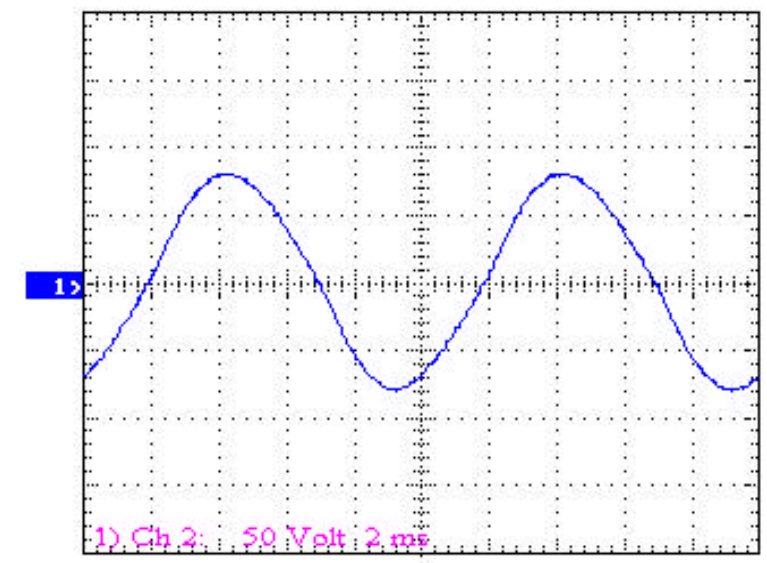

Figure 7. Terminal voltage across resistive load

\section{Parameter Determination Test}

A simple modified test is used to get the parameters of the permanent magnet [6]. The experiment is shown in Figure 8. 


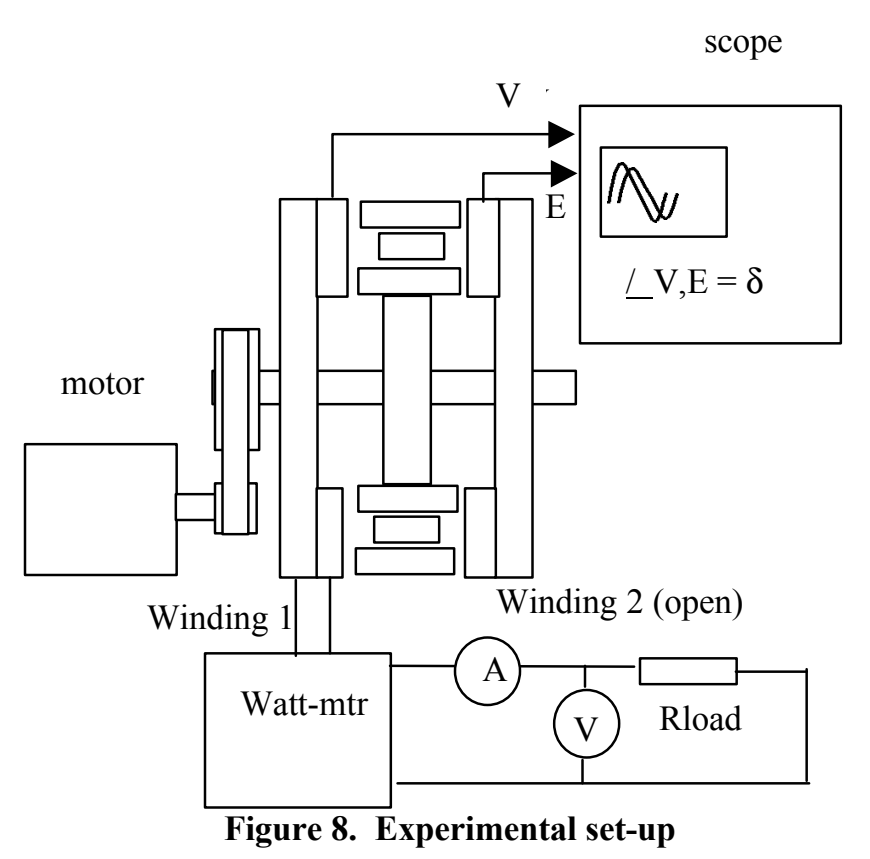

One side of the generator (winding 1) is connected to a rated load at unity power factor. The generator is driven to generate a rated frequency. The other side of the winding (winding 2) is an open circuit. The voltage output of winding 1 is called terminal voltage $\mathrm{V}$ and the open circuit voltage of winding 2 is called open circuit voltage E. The angle difference between $\mathrm{V}$ and $\mathrm{E}$ is called $\delta$, which is the torque angle of the generator at this load. The power, current, and voltage output of winding 1 is recorded.

The parameters can be computed from the test data, and the results are listed in Table 2 below.

Table 2. Results from Test Data

\begin{tabular}{|l|l|l|l|}
\hline Parameters & $\mathbf{L}_{\mathrm{ds}}$ & $\mathbf{L}_{\mathrm{qs}}$ & $\mathbf{R}_{\mathbf{s}}$ \\
\hline & $8.41 \mathrm{mH}$ & $4.38 \mathrm{mH}$ & $0.22 \mathrm{ohm}$ \\
\hline Vopen circuit & 75 volts & Vrated load & 58 volts \\
\hline Irated/winding & $11 \mathrm{Amp}$ & Prated/winding & 650 watt \\
\hline Rotor Speed & $667 \mathrm{rpm}$ & $100 \mathrm{~Hz}$ & \\
\hline
\end{tabular}

\section{CONCLUSION}

The proposed generator is investigated for application in wind power generation. In the first stage of implementation, a proof of concept of the generator is investigated. The magnetic and electric loading are shown to be within the limits of common practice of machine design. The generator has the following advantages for wind turbine generation:

- The modular concept is suitable for the commercial production of machines of limited quantities and with different sizes and output requirements. The components are manufactured on a per pole basis. The tooling required is minimized. The design can be readily changed, such as the number of poles in one unit or the number of unit modules in a generator system.

- The axial flux design makes it easier to increase the flux density in the air gap.

- The toroidal form of the stator winding makes it easy to fabricate. The geometry of the stator winding and stator core make the heat dissipation more effective.

- To scale up the output power of the generator, more units can be stacked in the axial directions. The power converter required to process the power is readily compatible with the generator. Each unit module of the generator is matched with each leg of the power switches.

\section{ACKNOWLEDMENTS}

The authors wish to thank Jerry Bianchi for his assistance during the test set up and Jim Adams for his help during the fabrication of this generator.

We wish to acknowledge our management at NREL and the U.S. Department of Energy (DOE) for encouraging us and approving the time and tools we needed for this project. DOE supported this work under contract number DE-AC3683CH10093.

\section{REFERENCES}

[1] B.J. Chalmers, E.Spooner, "An Axial-flux Permanentmagnet Generator for a Gearless Wind Energy System," PEDES 96, January 1996, New Delhi, India.

[2] F. Carrichi, F. Crescimbini, F. Mezzetti, "Multistage Axial-flux PM Machine for Wheel Direct Drive," IEEE Transactions on Industry Applications, Vol 32. No. 4, July/August 1996, pp. 882-887.

[3] E. Spooner, A. Williamson, "Modular, Permanent-magnet Wind-turbine Generators," Conference Record of the 1996 IEEE Industry Applications Society, Oct. 6-10, 1996, San Diego, California, Volume 1, pp. 497-502

[4] S. Huang, J. Luo, T.A. Lipo, "Analysis and Evaluation of the Transverse Flux Circumferential Current Machine," Conference Record of the 1997 IEEE Industry Applications Society, Oct. 5-9, 1997, New Orleans, Louisiana, Volume 1, pp. 378-384

[5] E.F. Fuchs, A.A. Fardoun, P.Carlin, R.W. Erikson, "Permanent Magnet Machines with Large Speed Variations," Windpower 92, October 1992, Seattle, Washington.

[6] Gieras, J.F., Wing, M., "Permanent Magnet Motor Technology, Design and Applications," Marcel Dekker, Inc. New York, 1997. 